\title{
Effect of Wetness Duration and Temperature on the Development of Anthracnose on Selected Almond Tissues and Comparison of Cultivar Susceptibility
}

\author{
J. Diéguez-Uribeondo, H. Förster, and J. E. Adaskaveg
}

First and third authors: Department of Plant Pathology and Microbiology, University of California, Riverside 92521; and second author: Department of Plant Pathology, University of California, Davis 95616. Current address of J. Diéguez-Uribeondo: Real Jardín Botánico, C.S.I.C., Madrid, 28014. Accepted for publication 15 April 2011.

\begin{abstract}
Diéguez-Uribeondo, J., Förster, H., and Adaskaveg, J. E. 2011. Effect of wetness duration and temperature on the development of anthracnose on selected almond tissues and comparison of cultivar susceptibility. Phytopathology 101:1013-1020.

Blossoms, leaves, fruit, and woody tissues of almond can be affected by anthracnose caused by Colletotrichum acutatum. Because the disease occurs throughout rainy spring seasons, the effect of temperature and wetness duration on disease development was evaluated in controlled studies. The lowest inoculum concentration where disease developed on leaves was $10^{4}$ conidia/ml. Longer wetness durations were needed for leaves than for blossoms and disease increased linearly with increasing wetness durations. Inoculation temperature mainly affected final disease levels. Temperature during incubation affected the rate of disease development, while final disease levels were very similar at 10,15 , or $20^{\circ} \mathrm{C}$. An analysis of covariance was performed to compare regressions of the effects of wetness and temperature on disease development for several

studies, a common slope model was statistically sufficient to describe all four cultivars. Cultivar Nonpareil (NP) had a significantly $(P<0.05)$ lower adjusted means at the midpoint than cultivars Carmel (CA), NePlus Ultra (NU), and Wood Colony (WC). For blossom inoculations at $20^{\circ} \mathrm{C}$ and for leaf inoculations at all temperatures evaluated, an unequal slope model was statistically justified for comparing regression lines. For blossoms, the slopes were significantly different $(P<0.05)$ for pair-wise comparisons of CA-NU, NU-WC, and NP-WC. For leaves, most of the cultivars responded differently to infection at different temperatures. Two of the pair-wise comparisons demonstrated unequal slopes at all three temperatures evaluated (i.e., NU-NP and NU-WC). Overall, for blossoms and leaves, NP was the least susceptible, NU was the most susceptible, and WC and CA showed an intermediate susceptibility. In field blossom and fruit studies, a common slope model was statistically sufficient to describe all four cultivars. NP had a significantly lower midpoint (i.e., was less susceptible) than $\mathrm{CA}$ or $\mathrm{WC}$, whereas no significant difference $(P>0.1)$ occurred in comparisons between $\mathrm{CA}$ and $\mathrm{WC}$.
\end{abstract} almond cultivars. For blossom inoculations at $15^{\circ} \mathrm{C}$ in growth-chamber
Anthracnose can be a serious disease of almond in California, causing major pre- and postharvest losses when environmental conditions are conducive $(1,2)$. Two distinct subpopulations of the causal fungus Colletotrichum acutatum J. H. Simmonds have been identified and characterized on almond in California, the pink and gray phenotypes (12). The pink phenotype is more common and has been shown to be more virulent at temperatures of 15 to $25^{\circ} \mathrm{C}(1,12)$. All of the currently grown almond cultivars can be affected by the disease (1); however, differences in disease incidence and severity among cultivars have been observed in the field: cultivar Nonpareil is the least susceptible, whereas others (e.g., Carmel, Wood Colony, and NePlus Ultra) are moderately to highly susceptible. Symptoms of blossom blight, sunken fruit lesions, irregular leaf lesions originating along the margin, and dieback of branches may occur at all stages of development $(1,18,19)$. All of these symptoms can directly or indirectly lead to reduced crop yields. Infected, mummified fruit on the tree are a major source of primary inoculum in the spring. Conidia are splash-dispersed by rain (1), as are conidia in other Colletotrichum spp.-host systems $(10,14,22)$. Field observations suggest that disease progress is favored by warm $\left(20\right.$ to $\left.25^{\circ} \mathrm{C}\right)$ and

Corresponding author: J. E. Adaskaveg; E-mail address: jim.adaskaveg@ucr.edu

doi:10.1094/PHYTO-07-10-0193

(c) 2011 The American Phytopathological Society wet weather. Thus, the extended susceptibility of several host tissues of all commercial almond cultivars make anthracnose a difficult disease to manage when environmental conditions are favorable.

Wetness duration and temperature are generally the main microclimatic parameters determining the development of fungal plant diseases. Thus, models to predict anthracnose and other foliar diseases in different host systems have been based on climatic parameters $(5,15,20,23,24)$, relationships between temperature and leaf wetness duration derived from experiments under controlled conditions $(4,16,17,21,25)$, and laboratory studies on conidial germination (11). Some of these models have been modified for particular climates and have allowed a significant improvement in the timing of fungicide applications $(20,24)$

To ultimately develop a prediction model and a forecasting system for almond anthracnose, we characterized temperaturewetness relationships for $C$. acutatum infections on almond in controlled studies in growth chambers and we evaluated the effect of wetness duration in the field. We determined the requirements for temperature and wetness duration for disease development on selected almond tissues to differentiate susceptibility of cultivars. Studies were conducted on blossoms and leaves of Nonpareil, Carmel, NePlus Ultra, and Wood Colony that, together, account for $>70 \%$ of the current almond acreage in California. The effect of inoculum concentration on disease development was also determined. 


\section{MATERIALS AND METHODS}

Fungal isolates and inoculum preparation. An isolate (isolate 1732) of the pink genotype subpopulation of $C$. acutatum from almond that was genetically characterized and tested for pathogenicity previously (12) was maintained on potato dextrose agar (Difco Laboratories, Detroit, MI). Conidial suspensions were prepared in sterile deionized water from 14-day-old cultures grown at $23 \pm 2{ }^{\circ} \mathrm{C}$. The pathogen was reisolated monthly from diseased tissues to maintain its capacity for abundant spore production.

Almond cultivation, inoculation, and rating of disease in growth-chamber studies. Carmel, NePlus Ultra, Nonpareil, and Wood Colony almond cultivars (Burchell Nursery, Oakdale, CA) were planted in 8-liter plastic pots. Trees were maintained in a greenhouse at 22 to $27^{\circ} \mathrm{C}$ and were kept pruned to a height of 30 to $60 \mathrm{~cm}$. Flowering was induced by incubating the trees at 4 to $5^{\circ} \mathrm{C}$ for 4 weeks and then returning them to the greenhouse where they started blooming after 5 to 7 weeks. For inoculation, a uniform layer of fine droplets of a conidial suspension was gently sprayed onto upper and lower blossom or leaf surfaces using an atomizer (Model 15-RD; DeVilbiss Health Care, Somerset, PA). In experiments with blossoms, at least 10 blossoms were sprayed per branch replication with $10^{5}$ conidia/ml. Disease incidence was calculated as the percentage of blighted blossoms of the total number of blossoms inoculated for each branch 10 days after inoculation. In experiments with leaves, the 5th to 14 th youngest leaves of a branch were inoculated with $10^{6}$ conidia $/ \mathrm{ml}$. Selected durations of wetness periods as described below were provided by covering inoculated branches or entire trees with clear plastic bags. Once plastic bags were removed, plants were allowed to air dry before being placed into incubation chambers. Disease was evaluated 18 days after inoculation (unless indicated otherwise). Disease incidence was calculated as the percentage of leaves with irregular necrotic lesions of the total number of leaves inoculated per branch, whereas severity was assessed as the average number of lesions per leaf for the total of 10 leaves evaluated for each replication.

Evaluation of the effect of inoculum concentration on disease development on leaves in growth-chamber studies. One branch on each of three trees of NePlus Ultra and Nonpareil was inoculated with conidial suspensions adjusted to $10^{3}, 10^{4}, 10^{5}$, or $10^{6}$ conidia/ml (a total of four inoculations per tree). The design was a one-way treatment structure in a randomized complete block design. The blocking factor was an individual plant for each cultivar. Trees were provided a 72-h wetness duration and were maintained at 15 or $20^{\circ} \mathrm{C}$ for the entire experimental period of 18 days. Disease severity on leaves was assessed as described above.

Evaluation of the effect of temperature and wetness duration on disease development in growth-chamber studies. Two time intervals were distinguished as described by Shaw et al. (21): (i) the inoculation period, which is the time interval from spraying plants with conidia to the end of the wetness period, and (ii) the incubation period, which is the time interval after the inoculation period until disease evaluation. The effect of temperature during the inoculation and incubation periods was evaluated on leaves of Carmel. Leaves were inoculated using a suspension of $10^{6}$ conidia/ml. To study the effect of temperature during a $72-\mathrm{h}$ inoculation period, three trees were used for each temperature evaluated $\left(10,15\right.$, and $\left.20^{\circ} \mathrm{C}\right)$ and three branches were inoculated per tree. The 72-h period was selected to ensure high infection. Trees were then moved to a growth chamber adjusted to $20^{\circ} \mathrm{C}$ for an additional 42 days. To study the effect of temperature during the incubation period, three branches of each of nine trees were sprayed with conidia of $C$. acutatum as described above and incubated at $20^{\circ} \mathrm{C}$ during the 72 -h inoculation period. Three trees each were then moved to growth chambers at 10,15 , or $20^{\circ} \mathrm{C}$ for
42 days. The design was a one-way treatment structure in a randomized complete block design. The blocking factor was the inoculation or incubation growth chamber set at each temperature for the two experiments, respectively.

Wetness duration-temperature relationships were compared for blossoms and leaves of Carmel, Wood Colony, Nonpareil, and NePlus Ultra almond. Temperatures were the same during the entire experimental periods and were 15 or $20^{\circ} \mathrm{C}$ for blossoms and 15,20 , or $25^{\circ} \mathrm{C}$ for leaves. For each temperature, three trees of each cultivar were inoculated $\left(10^{5}\right.$ conidia/ml for blossoms and $10^{6}$ conidia/ml for leaves) and, for each wetness duration evaluated $(3,24$, and $48 \mathrm{~h}$ for blossoms; 3, 12, 24, 48, and $72 \mathrm{~h}$ for leaves), one branch of each tree was selected. The experimental design was as described in the paragraph above.

Evaluation of the effect of wetness duration on disease incidence of blossoms and fruit in field studies. Experiments were conducted on 5- to 6-year-old Carmel, Nonpareil, and Wood Colony trees in an orchard at the University of California at Riverside field station. Blossoms were inoculated with $C$. acutatum at $10^{5}$ conidia/ml and fruit at $10^{6}$ conidia/ml using a hand sprayer, and inoculated branches were covered with clear plastic bags. For each wetness duration $(3,24,48$, or 72 h), flowers or fruit of one branch for each of three tree replications for each cultivar were used in each of two experiments. The design was a one-way treatment structure in a randomized complete block design. The blocking factor was an individual tree for each cultivar. To monitor temperature, two sensors (HOBO; Onset Computer Corp., Pocasset, MA) were attached to representative branches. For blossoms, disease incidence was quantified 10 days after inoculation. For fruit, disease severity was rated 18 days after inoculation using a scale from 0 to 5 based on the percentage of fruit surface affected, with $0=$ no symptoms and $1=\leq 20,2=21$ to $40,3=41$ to $60,4=50$ to 80 , and $5=>80 \%$ of the fruit surface diseased.

Statistical analyses of data. All experiments were done two or three times. For repeated experiments, the homogeneity of variances was tested using Bartlett's test of homogeneity. Variances were homogeneous and data were combined for further statistical analysis. Incidence values for disease were arcsine transformed. Data for inoculum concentration and wetness duration studies were analyzed using analysis of variance and regression analysis (SAS, version 9.2; SAS Institute, Cary, NC). Response curves of disease severity on inoculum concentration were also fit to nonlinear models (SigmaPlot version 10; Systat Software, San Jose, $\mathrm{CA}$ ). Analysis of covariance was used to evaluate inoculum concentration or wetness duration on the incidence or severity of disease at selected temperatures using mixed-model procedures (13). Additionally, cultivar differences in disease susceptibility at each temperature were evaluated. For this, data were compared to determine whether the slopes of the regression lines were equal to zero (null hypothesis) and whether the regressions had a common slope. When slopes were not equal to zero and when slopes were unequal, an "unequal slope model" was used to compare the cultivars. An unequal slope model is a model fitted to regressions for different groups (i.e., cultivars) with slopes known to be different. Additionally, data were grouped for pair-wise comparisons and only regression lines with common slopes were compared for adjusted means (least square means [LSMeans]) at the midpoint.

\section{RESULTS}

Evaluation of the effect of inoculum concentration on disease development on leaves in growth-chamber studies. On NePlus Ultra at both inoculation period temperatures tested (15 and $20^{\circ} \mathrm{C}$ ) and on Nonpareil at $15^{\circ} \mathrm{C}$, disease severity assessed 18 days after inoculation increased log-linearly with increasing inoculum concentrations between $10^{3}$ and $10^{6}$ conidia/ml (Fig. 1A and B). At $20^{\circ} \mathrm{C}$ for Nonpareil, however, disease severity in- 
creased exponentially (two-parameter exponential growth curve) with increasing concentrations of inoculum (Fig. 1B). For both cultivars, the lowest inoculum concentration that resulted in disease development was $10^{4}$ conidia/ml. For each cultivar, an analysis of covariance (using linear regressions of disease severity on inoculum concentration at each temperature) indicated that the slopes were different (data not shown) and that disease severity was higher at 20 than at $15^{\circ} \mathrm{C}$.

Evaluation of the effect of temperature and wetness duration on disease development in growth-chamber studies. The effect of temperature during the inoculation and incubation periods on anthracnose development on leaves is illustrated in Figure 2A and B, respectively. Final disease levels depended on temperatures during the inoculation period but not on temperatures during incubation. Temperatures during incubation, however, determined the rate of disease development. At 15 or $20^{\circ} \mathrm{C}$ during the inoculation period, disease symptoms were first visible 10 days after inoculation (Fig. 2A). Within an additional 4 days of incubation, disease increased to final average severities of $\approx 1$ or 1.6 lesions/leaf for 15 or $20^{\circ} \mathrm{C}$, respectively. At an inoculation temperature of $10^{\circ} \mathrm{C}$, disease levels reached a maximum of $<0.1$ lesions/leaf $\approx 20$ days after inoculation and remained at this level for the entire experimental period of 45 days.

Final disease levels were not significantly different $(P>0.05)$ when plants were kept at $20^{\circ} \mathrm{C}$ during the inoculation period and

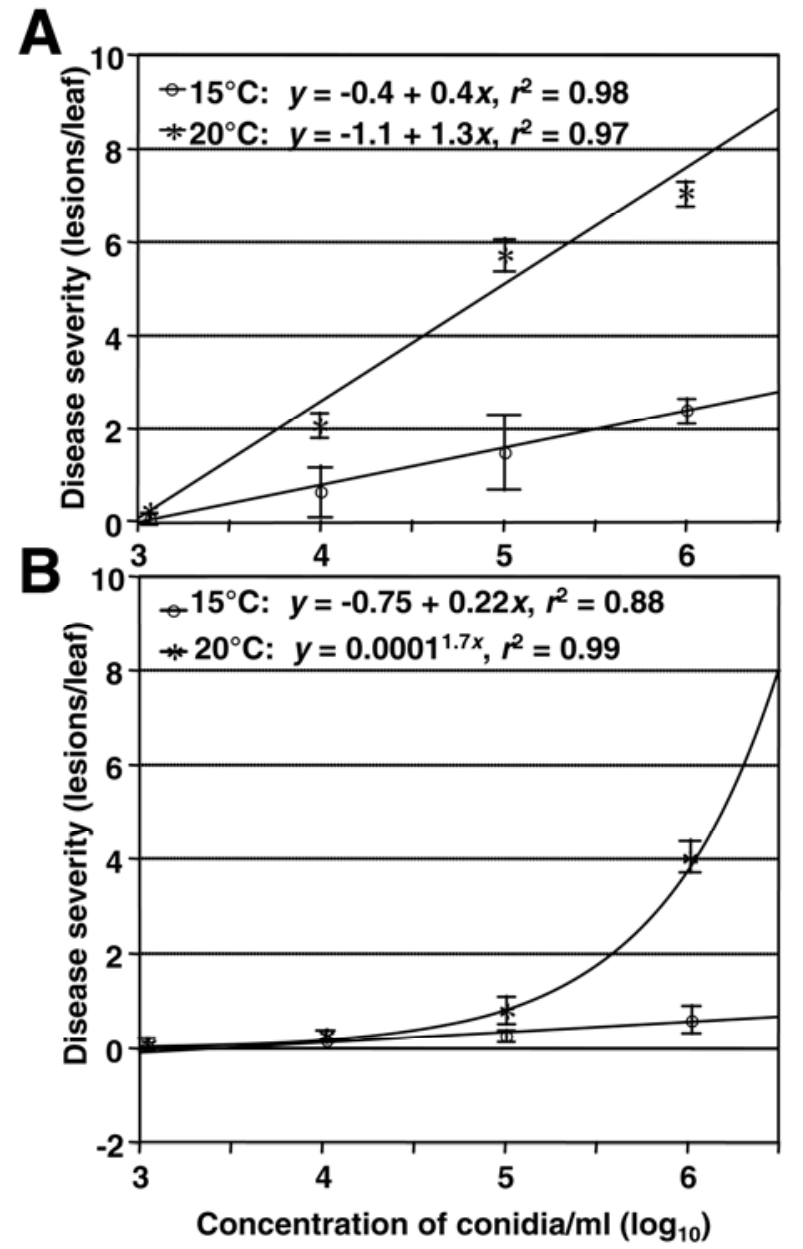

Fig. 1. Regression of inoculum concentration of Colletotrichum acutatum on disease development on leaves of almond $\mathbf{A}$, NePlus Ultra and $\mathbf{B}$, Nonpareil. Plants were inoculated with conidial suspensions adjusted to $10^{3}, 10^{4}, 10^{5}$, or $10^{6}$ conidia/ml, provided a 72-h wetness duration, and were maintained at 15 or $20^{\circ} \mathrm{C}$ for the entire experimental period of 18 days. Disease severity was evaluated as number of lesions per leaf. Bars represent the standard error of each mean. were then moved to incubation temperatures of 10,15 , or $20^{\circ} \mathrm{C}$ (Fig. 2B). Disease, however, progressed much more rapidly at 15 or $20^{\circ} \mathrm{C}$ compared with $10^{\circ} \mathrm{C}$. Thus, for both 15 and $20^{\circ} \mathrm{C}$, disease symptoms were first visible 10 days after inoculation and increased to final average severities of $\approx 1.5$ to 1.6 lesions/leaf 13 or 15 days after inoculation. Incubation at $10^{\circ} \mathrm{C}$ resulted in a much slower rate of disease development. Symptoms were first visible after 20 days and the final average disease severity of 1.4 lesions/leaf was observed 45 days after inoculation.

Wetness duration-temperature relationships during the inoculation period for blossoms of four cultivars of almond are illustrated for 15 and $20^{\circ} \mathrm{C}$ in Figure $3 \mathrm{~A}$ and B, respectively. At both temperatures and for all cultivars, a 3-h wetness period resulted in an average disease incidence of $\approx 20 \%$. Incidence increased with increasing wetness duration from 3 to $48 \mathrm{~h}$. For all cultivars, the average incidence of diseased blossoms using a 48-h wetness period was $>50 \%$ at both temperatures. For leaves, disease severity also increased with increasing wetness durations (Fig. 4A to C). In contrast to blossoms, however, longer wetness periods (a minimum of $24 \mathrm{~h}$ ) were required for disease development on all four almond cultivars, and final disease levels remained low $(<2.5$ lesions/leaf) at an incubation temperature of $15^{\circ} \mathrm{C}$ (Fig. 4A). High levels of disease, with an average of $>6$ lesions/leaf, only developed on NePlus Ultra using a $\geq 48$-h wetness duration at $25^{\circ} \mathrm{C}$ or a 72 -h wetness duration at $20^{\circ} \mathrm{C}$ (Fig. 4B and C). Overall, disease generally progressed most slowly on Nonpareil compared with the other three cultivars. Equations for regression lines, as
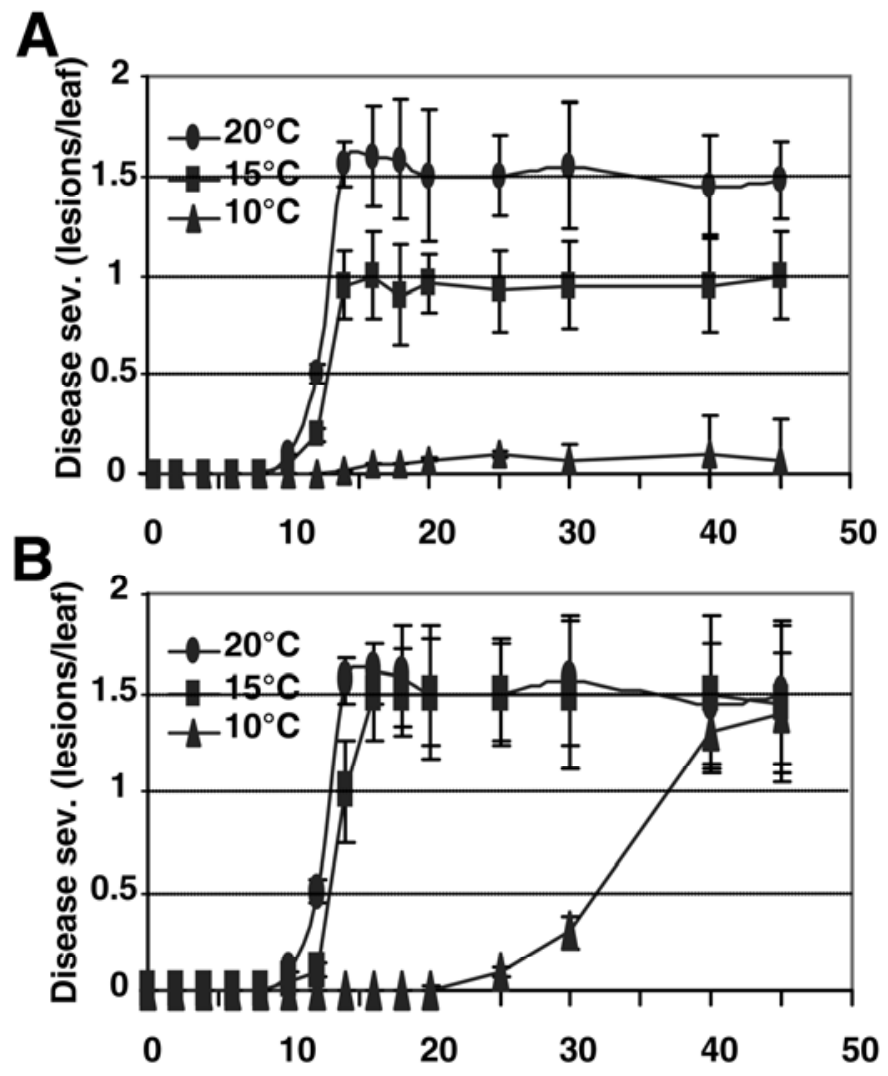

Time after inoculation (days)

Fig. 2. Effect of temperature during $\mathbf{A}$, the inoculation period (i.e., time from inoculation until the end of the wetness period) and $\mathbf{B}$, the incubation period (i.e., time interval after the inoculation period) on development of anthracnose lesions on leaves of almond Carmel. Trees were inoculated with Colletotrichum acutatum at $10^{6}$ conidia/ml, provided with a $72-\mathrm{h}$ wetness period at 10 , 15 , or $20^{\circ} \mathrm{C}$, and incubated at $20^{\circ} \mathrm{C}$ for an additional 42 days. Alternatively, trees were inoculated and provided a wetness period at $20^{\circ} \mathrm{C}$ and incubated at 10,15 or $20^{\circ} \mathrm{C}$. Bars represent the standard error of each mean. 
well as $r^{2}$ and probability values of models for blossoms and leaves, are shown in Table 1.

Evaluation of the effect of wetness duration on disease development on blossoms and fruit in field studies. Minimum, maximum, and average daily temperatures in the field were 0.5 to $8.2^{\circ} \mathrm{C}$ (mean $5.0^{\circ} \mathrm{C}$ ), 9.1 to $19.3^{\circ} \mathrm{C}$ (mean $14.2^{\circ} \mathrm{C}$ ), and 6.7 to $12.2^{\circ} \mathrm{C}$ (mean $9.4^{\circ} \mathrm{C}$ ), respectively, during the blossom studies and 10.6 to $18.8^{\circ} \mathrm{C}$ (mean $14.8^{\circ} \mathrm{C}$ ), 20.5 to $36.3^{\circ} \mathrm{C}$ (mean $29.1^{\circ} \mathrm{C}$ ), and 16.8 to $26.5^{\circ} \mathrm{C}$ (mean $20.9^{\circ} \mathrm{C}$ ), respectively, for the fruit studies. As in the growth-chamber studies, disease progressed linearly with increasing wetness periods on the three cultivars of almond evaluated (Fig. 5; Table 1). For both blossoms and fruit, final disease levels were lowest on Nonpareil and highest on Wood Colony.

Almond cultivar susceptibility to anthracnose in growthchamber and field studies. Cultivars were compared using an analysis of covariance of linear regression of disease severity or incidence on wetness duration for each of the temperatures and almond tissues evaluated (Table 2). For each temperature, cultivar, and tissue, the null hypothesis that the slopes of the regression lines were equal to zero was rejected $(P<0.05)$. For blossom inoculations in growth-chamber studies at $15^{\circ} \mathrm{C}$, a common slope model was statistically sufficient $(P=0.543)$ to describe all four cultivars. Pair-wise LSMeans midpoint comparisons of regression lines for these inoculations were the same $(P>0.05)$ for Carmel and NePlus Ultra, Carmel and Wood Colony, and NePlus Ultra and Wood Colony (Table 2). Significant differences $(P<0.05)$ of LSMean midpoints were found for comparisons of Nonpareil
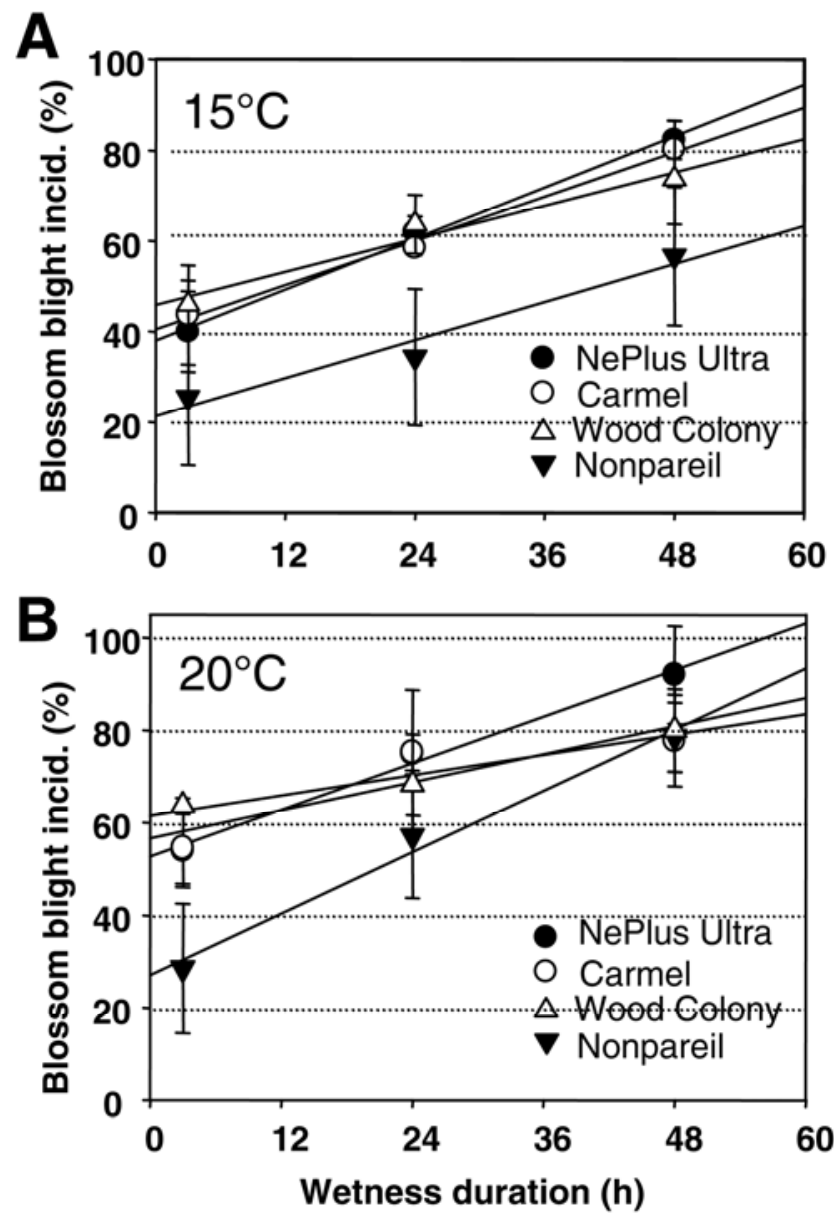

Fig. 3. Regression of wetness duration (i.e., length of the inoculation period) on the incidence of blossom blight of almond NePlus Ultra, Wood Colony, Carmel, and Nonpareil after inoculation with Colletotrichum acutatum and incubation of plants at a constant temperature of $\mathbf{A}, 15^{\circ} \mathrm{C}$ or $\mathbf{B}, 20^{\circ} \mathrm{C}$ in growth-chamber studies. Bars represent the standard error of each mean. with Carmel, NePlus Ultra, and Wood Colony. Nonpareil was the least susceptible cultivar in these studies (Fig. 3A; Table 2).

For blossom inoculations in growth-chamber studies at $20^{\circ} \mathrm{C}$, a common slope model was not statistically justified $(P=0.011)$. Using an unequal slope model, pair-wise comparisons of regression lines of cultivars were significantly different $(P<0.05)$ for some of the comparisons, indicating that disease developed differently on some cultivars for the wetness durations evaluated (Table 2). This was found for comparisons between Carmel and NePlus Ultra, NePlus Ultra and Wood Colony, and Nonpareil and Wood Colony. LSMeans of midpoints for comparisons with equal slopes again indicated that disease incidence on Nonpareil was signifi-
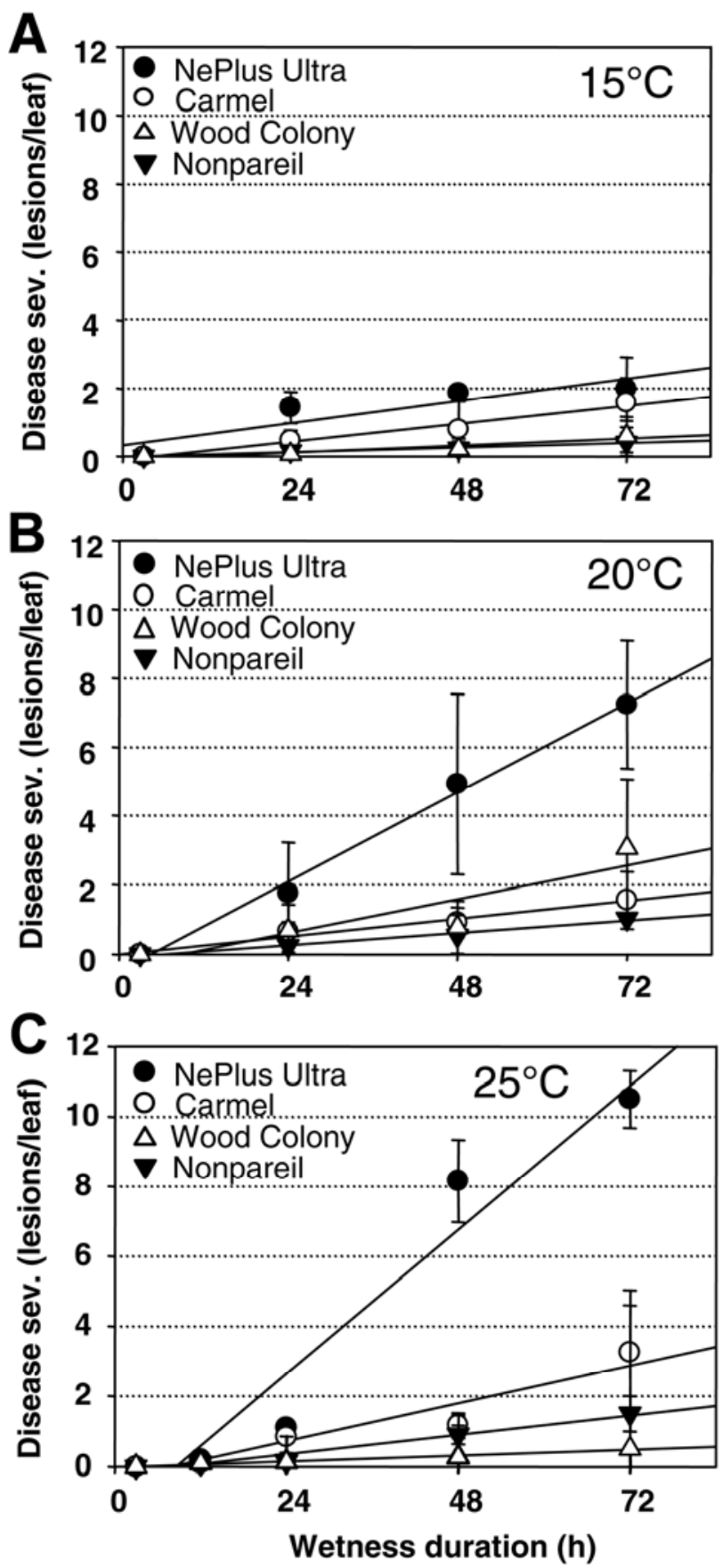

Fig. 4. Regression of wetness duration (i.e., length of the inoculation period) on the severity of anthracnose on leaves of almond NePlus Ultra, Wood Colony, Carmel, and Nonpareil after inoculation with Colletotrichum acutatum and incubation of plants at constant temperatures of $\mathbf{A}, 15^{\circ} \mathrm{C} ; \mathbf{B}, 20^{\circ} \mathrm{C}$; or $\mathbf{C}, 25^{\circ} \mathrm{C}$ in growth-chamber studies. Bars represent the standard error of each mean. 
cantly $(P<0.05)$ lower than on Carmel and NePlus Ultra, whereas regression lines for Carmel and Wood Colony were similar in slope and LSMeans midpoints (Fig. 3B; Table 2).

For leaf inoculations in growth-chamber studies at all temperatures evaluated, a common slope model was not statistically justified $(P \leq 0.008)$. Using an unequal slope model, four, three, and four of the total of six pair-wise cultivar comparisons had significantly different slopes $(P<0.05)$ of the regression lines for inoculations at 15,20 , and $25^{\circ} \mathrm{C}$, respectively. However, there was no consistent response for any of these pair-wise comparisons (i.e., none of the cultivar pairs demonstrated an equal slope at all three temperatures evaluated). Thus, cultivars responded differently to infection by $C$. acutatum at different temperatures. Two of the pair-wise cultivar comparisons had significantly different $(P<0.05)$ slopes at all three temperatures evaluated (i.e., NePlus Ultra-Nonpareil and NePlus Ultra-Wood Colony).

Overall, these results from regressions of disease on wetness duration at selected temperatures indicated that relative disease susceptibility among cultivars was similar for blossoms and leaves. Nonpareil was the least susceptible cultivar, whereas NePlus Ultra was the most susceptible and Wood Colony and Carmel showed an intermediate susceptibility.

In pair-wise comparisons of three cultivars used in blossom and fruit inoculations in the field, a common slope model was statistically sufficient to describe all four cultivars $(P=0.223$ for blossoms and $P=0.116$ for fruit) (Table 2). LSMeans midpoint comparisons for both tissues indicated consistently that Nonpareil had a significantly lower midpoint (i.e., was less susceptible) than Carmel or Wood Colony, whereas no significant difference $(P>$ 0.1 ) occurred in comparisons between Carmel and Wood Colony (i.e., were similar in susceptibility).

\section{DISCUSSION}

In this study, temperature and wetness duration conditions that favor the development of anthracnose of almond caused by $C$. acutatum were defined for selected host tissues, and this allowed comparisons of the susceptibility among cultivars that currently represent a majority of the planted acreage in California. The temperature range evaluated, 10 to $25^{\circ} \mathrm{C}$, reflects orchard conditions in California between March and late spring (i.e., late May), when anthracnose is commonly observed. Leaves and blossoms were used in the growth-chamber experiments, although economic losses from anthracnose are most important on fruit. Sufficient amounts of fruit, however, are difficult to obtain in the greenhouse, whereas leaves are readily available. In field studies, we used blossoms and fruit, and the field blossom data validated our growth-chamber studies with blossoms. Field observations have suggested that environmental conditions conducive for anthracnose development are very similar for leaves and fruit (J. E. Adaskaveg, unpublished). In our studies, disease evaluation was based on incidence for blossoms and severity for leaves and fruit. This was done because, in most cases, diseased blossoms became completely blighted, whereas distinct lesions developed on leaves and fruit.

We found that wetness duration and temperature were critical microclimatic parameters for anthracnose development. Disease only developed when inoculations were followed by a period of wetness. This is in agreement with observations by others showing that germination of conidia of Colletotrichum spp. is negligible in the absence of free moisture (26). The length of wetness period required for disease development depended on the temperature during the experiment. Thus, at higher temperatures $\left(20\right.$ and $25^{\circ} \mathrm{C}$ ), shorter wetness durations were sufficient whereas, at lower temperatures $\left(10^{\circ} \mathrm{C}\right)$, longer durations of wetness were needed. This corresponded with growth rates of the pathogen at these temperatures (12). In our field studies, disease also increased with increasing length of wetness durations. Longer wetness periods, however, were required for disease to appear on blossoms compared with the growth-chamber studies under controlled conditions, most likely because low night temperatures in the spring limited the advance of infections. These results are

TABLE 1. Regressions of anthracnose incidence (on blossoms) or severity (on leaves and fruit) on wetness duration after inoculation of selected almond cultivars with conidia of Colletotrichum acutatum at different temperatures in growth chamber and field studies

\begin{tabular}{|c|c|c|c|c|c|}
\hline Tissue & Temperature $\left({ }^{\circ} \mathrm{C}\right)$ & Cultivar & Regression equation $^{\mathrm{a}}$ & $r^{2}$ & $P>F^{\mathrm{b}}$ \\
\hline \multirow[t]{7}{*}{ Blossoms } & \multirow[t]{3}{*}{15} & Carmel & $y=0.815 x+40.40$ & 0.858 & $0.0003^{*}$ \\
\hline & & NePlus Ultra & $y=0.938 x+38.00$ & 0.922 & $0.0001 *$ \\
\hline & & Nonpareil & $y=0.670 x+21.30$ & 0.510 & $0.030^{*}$ \\
\hline & \multirow[t]{4}{*}{20} & Carmel & $y=0.506 x+56.55$ & 0.590 & $0.016^{*}$ \\
\hline & & NePlus Ultra & $y=0.841 x+52.63$ & 0.742 & $0.003 *$ \\
\hline & & Nonpareil & $y=1.105 x+27.10$ & 0.802 & $0.001 *$ \\
\hline & & Wood Colony & $y=0.367 x+61.47$ & 0.578 & $0.034 *$ \\
\hline & \multirow{2}{*}{15} & Nonpareil & $y=0.006 x-0.009$ & 0.392 & $0.029 *$ \\
\hline & & Wood Colony & $y=0.040 x-0.348$ & 0.403 & $0.026^{*}$ \\
\hline & \multirow[t]{4}{*}{20} & Carmel & $y=0.022 x-0.001$ & 0.647 & $0.002 *$ \\
\hline & & NePlus Ultra & $y=0.107 x-0.485$ & 0.785 & $0.0001 *$ \\
\hline & & Nonpareil & $y=0.015 x-0.090$ & 0.684 & $0.001 *$ \\
\hline & & Wood Colony & $y=0.040 x-0.353$ & 0.499 & $0.010 *$ \\
\hline & 25 & Carmel & $y=0.045 x-0.368$ & 0.689 & $0.0001 *$ \\
\hline & \multirow{2}{*}{ Field $^{c}$} & Nonpareil & $y=0.355 x-0.766$ & 0.615 & $0.020 *$ \\
\hline \multirow{4}{*}{ Fruit } & & Wood Colony & $y=0.910 x+5.763$ & 0.520 & $0.043^{*}$ \\
\hline & \multirow[t]{3}{*}{ Field } & Carmel & $y=0.053 x-0.242$ & 0.759 & $0.024 *$ \\
\hline & & Nonpareil & $y=0.030 x-0.108$ & 0.713 & $0.034 *$ \\
\hline & & Wood Colony & $y=0.061 x-0.184$ & 0.855 & $0.008^{*}$ \\
\hline
\end{tabular}

${ }^{a}$ Regression lines were determined using an analysis of variance and regression statistics for data from two to three growth-chamber and field experiments. Correlation coefficient $\left(r^{2}\right)$ and probability values are shown.

${ }^{\mathrm{b}}$ An asterisk denotes significance at $P<0.05$.

${ }^{\mathrm{c}}$ Variable temperatures under field conditions (see text for details). 

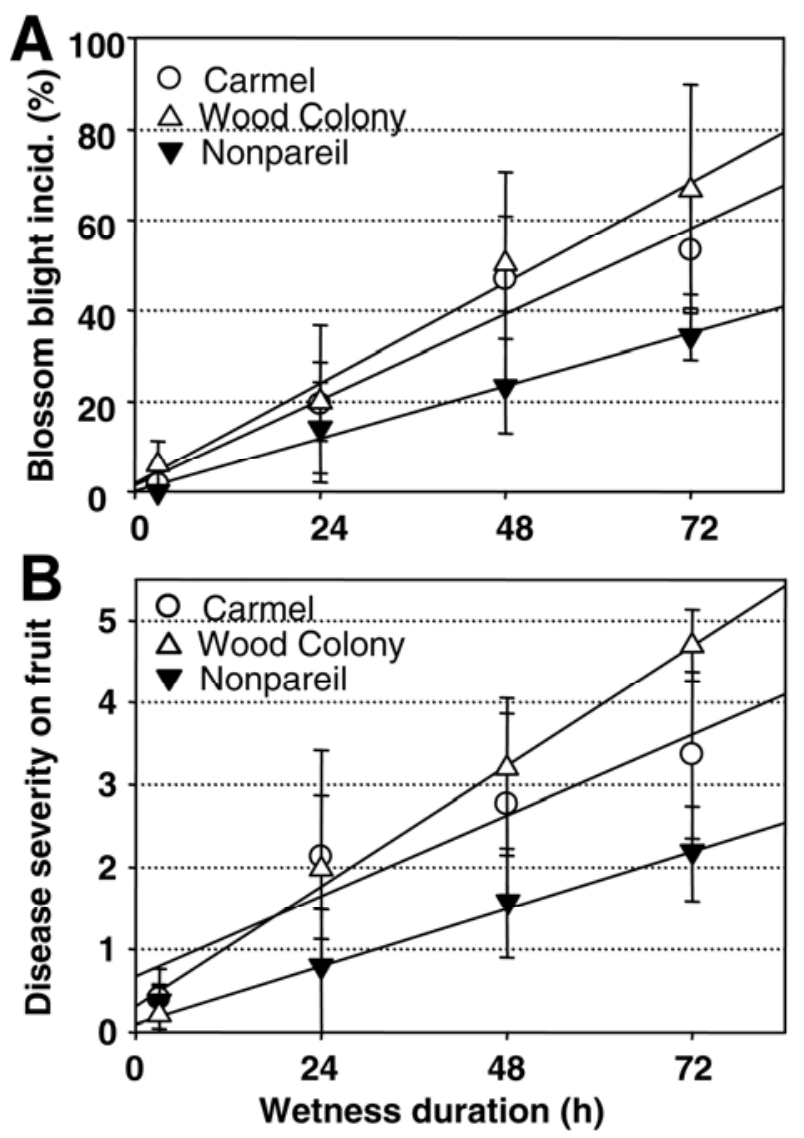

Fig. 5. Regression of wetness duration (length of the inoculation period) on the $\mathbf{A}$, incidence of blossom blight and $\mathbf{B}$, severity of anthracnose on fruit of almond Wood Colony, Carmel, and Nonpareil after inoculation with Colletotrichum acutatum in field studies. Severity on fruit was rated using a scale from 0 to 5 based on the percentage of fruit surface affected, where $0=$ no symptoms and $1=\leq 20,2=21$ to $40,3=41$ to $60,4=50$ to 80 , and $5=>80 \%$ of the fruit surface diseased. Bars represent the standard error of each mean.

in agreement with field observations on almond anthracnose that indicated that temperatures $>17^{\circ} \mathrm{C}$ and wetness durations $>96 \mathrm{~h}$ were more conducive for disease development than lower temperatures and shorter wetness periods (1). Similar effects of wetness period and temperature on disease development have been described for other Colletotrichum spp. on various hosts such as strawberry (27), citrus (23), and azalea (3).

The effect of temperature on disease development was studied in more detail by differentiating between temperature during the inoculation period and during the subsequent incubation period. Disease development was affected differently by temperatures during these two periods. Thus, inoculation temperature mainly affected final disease levels, whereas temperature during the incubation period affected the rate of disease development while final disease levels were very similar for incubation temperatures of 10,15 , and $20^{\circ} \mathrm{C}$.

An inoculation period at $20^{\circ} \mathrm{C}$ resulted in higher disease levels than one at $15^{\circ} \mathrm{C}$. The increase in disease at these temperatures when wetness periods $>24 \mathrm{~h}$ were provided cannot be easily explained. Previous microscopic studies indicated that, after $24 \mathrm{~h}$ at $20^{\circ} \mathrm{C}$, most conidia have germinated and formed appressoria and infection pegs (6). Extended wetness periods, however, may allow for secondary conidia to form, thus increasing the amount of inoculum and subsequent secondary infections. Alternatively, long wetness periods possibly compromise host defenses and allow colonizing hyphae to invade the host tissue and establish a successful infection that results in disease at a high incidence.

At an inoculation temperature of $10^{\circ} \mathrm{C}$, only a few lesions developed, even though plants were moved after 3 days to an incubation temperature of $20^{\circ} \mathrm{C}$ and were observed for up to 45 days. This lack of disease development can be explained by our previous studies on the early development of $C$. acutatum (7). In these studies, conidial germination on leaves was considerably delayed during an inoculation (wetness) period at $15^{\circ} \mathrm{C}$ as compared with $20^{\circ} \mathrm{C}$. At $10^{\circ} \mathrm{C}, 96 \mathrm{~h}$ were required to reach a germination rate of $40 \%$. Additionally, at this latter temperature, only $5 \%$ of the germinated spores formed appressoria after $72 \mathrm{~h}$ and there was no further increase after $72 \mathrm{~h}$ of incubation. Disease severity was found to increase linearly with the number of appressoria formed (7). Low final disease levels that occurred when the inoculation took place at low temperatures were probably due to the formation of few or no appressoria during the wetness period at low temperatures. When a temperature of $20^{\circ} \mathrm{C}$ was provided during the inoculation period, temperatures of 10 to $20^{\circ} \mathrm{C}$ during the incubation period affected only the rate of disease development but not the final level of disease. Thus, once conidia have germinated, appressoria have formed, and infection has advanced past a critical stage during favorable conditions, subsequent temperature conditions only define disease progress over time.

Disease also developed at different rates on blossom and leaf tissues in the growth-chamber experiments. Much higher levels of disease were found on blossoms at inoculation or incubation temperatures of 15 and $20^{\circ} \mathrm{C}$ using a 3-h wetness period compared with a 24-h wetness period for leaves at the same temperatures, indicating that blossoms are more susceptible. This again correlates with our microscopic observations on the early development of the pathogen, where conidial germination occurred faster on flower petals than on leaves $(6,7)$.

In comparisons of four almond cultivars in respect to susceptibility against anthracnose, overall, Nonpareil was the least susceptible. This cultivar comprises $\approx 50 \%$ of the almond acreage in California due its high nut quality. Additional cultivars are grown in each orchard, usually by row, to serve as pollinators of Nonpareil to ensure a high yield and to fulfill special market needs for a specific nut type. NePlus Ultra, Wood Colony, and Carmel are currently among the primary pollinators and, among these, NePlus Ultra was the most susceptible in our studies. This ranking of Nonpareil and NePlus Ultra is supported by numerous field observations over the years validating our experimental approach. Wood Colony and Carmel demonstrated an intermediate susceptibility in our studies that was not consistent under the different temperature-wetness conditions used. The variable susceptibility of these latter cultivars reflects observations of inconsistent disease incidence and severity on these and some other cultivars in field studies (J. E. Adaskaveg, unpublished).

Inoculum concentration was also found to be critical for disease development on the less susceptible Nonpareil and the more susceptible NePlus Ultra. For NePlus Ultra at both temperatures evaluated and for Nonpareil at $15^{\circ} \mathrm{C}$, a log-linear relationship with positive slopes was found between inoculum concentration and disease severity. For Nonpareil at $20^{\circ} \mathrm{C}$, however, an exponential growth model best described the data and increasing inoculum levels led to an exponential increase in disease. In the current studies, symptom development on leaves of both cultivars required a minimum inoculum concentration of $10^{4}$ conidia $/ \mathrm{ml}$ at both 15 and $20^{\circ} \mathrm{C}$, suggesting that a certain threshold level of successful infections is required for an advance in host colonization and disease development. Microscopic observations have demonstrated that, within $12 \mathrm{~h}$ at 20 to $25^{\circ} \mathrm{C}, \approx 70 \%$ of conidia generally germinate and $90 \%$ of the germinated conidia form appressoria on Carmel $(6,7)$. Although appressorium formation was lower on the less susceptible Nonpareil compared with the more susceptible Carmel (9), an exponential increase occurred at inoculum concentrations of $10^{4}$ to $10^{6}$ for Nonpareil. This provides further support for the necessity of a threshold for substantial symptom development. Modulation of the host $\mathrm{pH}$ environment by $C$. acutatum has been demonstrated previously (8). 


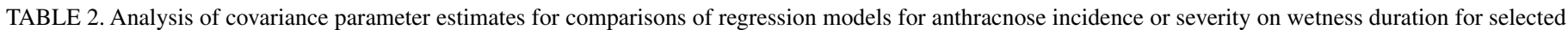
cultivars of almond in growth chamber and field studies

\begin{tabular}{|c|c|c|c|c|c|c|c|c|c|c|c|c|c|}
\hline \multirow[b]{2}{*}{ Tissue } & \multirow[b]{2}{*}{ Temperature } & \multirow{2}{*}{$\begin{array}{l}P \text { values for } \\
\text { the common } \\
\text { slope } \\
\text { hypothesis }\end{array}$} & \multirow{2}{*}{$\begin{array}{l}\text { Pair-wise } \\
\text { comparison }^{\mathrm{b}}\end{array}$} & \multicolumn{5}{|c|}{$\begin{array}{l}\text { Unequal slope modelc: } \\
\text { test of equality of slopes }\end{array}$} & \multicolumn{5}{|c|}{$\begin{array}{l}\text { Common slope model }{ }^{\mathrm{d}} \text { : } \\
\text { comparisons by LSMeans at midpoints }\end{array}$} \\
\hline & & & & Estimate & SE & df & $t$ value & $P>|t|$ & Difference ${ }^{\mathrm{e}}$ & SE & df & $t$ value & $P>|t|$ \\
\hline \multirow[t]{12}{*}{ Blossoms } & $15^{\circ} \mathrm{C}$ & 0.543 & CA vs. NU & \multirow{6}{*}{\multicolumn{5}{|c|}{ Common slope model followed }} & 0.633 & 4,281 & 29 & 0.15 & 0.883 \\
\hline & & & CA vs. NP & & & & & & 22.00 & 4,281 & 29 & 5.29 & $0.0001 * \mathrm{f}$ \\
\hline & & & CA vs. WC & & & & & & -0.30 & 4,281 & 29 & 0.08 & 0.938 \\
\hline & & & NU vs. NP & & & & & & 22.63 & 4,281 & 29 & 5.14 & $0.0001 *$ \\
\hline & & & NU vs. WC & & & & & & 0.333 & 4,281 & 29 & -0.07 & 0.9450 \\
\hline & & & NP vs. WC & & & & & & -22.30 & 4,281 & 29 & 5.21 & $0.0001^{*}$ \\
\hline & \multirow[t]{6}{*}{$20^{\circ} \mathrm{C}$} & \multirow[t]{6}{*}{$0.011 *$} & CA vs. NU & -0.599 & 0.223 & 26 & -2.68 & $0.012 *$ & & & & & \\
\hline & & & CA vs. NP & -0.335 & 0.223 & 26 & -1.50 & 0.145 & 27.89 & 5,674 & 28 & 4.92 & $0.0001 *$ \\
\hline & & & CA vs. WC & -0.139 & 0.223 & 26 & 0.62 & 0.531 & $-1,433$ & 4,090 & 28 & -0.35 & 0.7200 \\
\hline & & & NU vs. NP & 0.264 & 0.223 & 26 & 1.18 & 0.248 & -18.93 & 4,090 & 28 & -4.63 & $0.0001^{*}$ \\
\hline & & & NU vs. WC & 0.738 & 0.223 & 26 & 3.31 & $0.003 *$ & & & & & \\
\hline & & & NP vs. WC & 0.475 & 0.223 & 26 & 2.12 & $0.043^{*}$ & & & & & \\
\hline \multirow[t]{18}{*}{ Leaves } & \multirow[t]{6}{*}{$15^{\circ} \mathrm{C}$} & \multirow[t]{6}{*}{$0.008^{*}$} & CA vs. NU & -0.005 & 0.007 & 38 & -0.75 & 0.458 & \multirow[t]{5}{*}{-0.612} & \multirow[t]{5}{*}{0.176} & \multirow[t]{5}{*}{40} & \multirow[t]{5}{*}{-3.47} & \multirow[t]{6}{*}{$0.001 *$} \\
\hline & & & CA vs. NP & 0.016 & 0.007 & 38 & 2.36 & $0.023 *$ & & & & & \\
\hline & & & CA vs. WC & 0.013 & 0.007 & 38 & 1.95 & $0.049 *$ & & & & & \\
\hline & & & NU vs. NP & 0.022 & 0.007 & 38 & 3.11 & $0.003^{*}$ & & & & & \\
\hline & & & NU vs. WC & 0.019 & 0.007 & 38 & 2.70 & $0.010 *$ & & & & & \\
\hline & & & NP vs. WC & -0.003 & 0.007 & 38 & -0.41 & 0.686 & -0.022 & 0.176 & 40 & -0.12 & \\
\hline & \multirow[t]{6}{*}{$20^{\circ} \mathrm{C}$} & \multirow[t]{6}{*}{$0.0001 *$} & CA vs. NU & -0.086 & 0.016 & 38 & 5.38 & $0.0001 *$ & & & & & \\
\hline & & & CA vs. NP & 0.007 & 0.016 & 38 & 0.41 & 0.6810 & 0.333 & 0.420 & 40 & 0.79 & 0.432 \\
\hline & & & CA vs. WC & -0.019 & 0.016 & 38 & -1.19 & 0.2420 & -0.349 & 0.420 & 40 & -0.83 & 0.410 \\
\hline & & & NU vs. NP & 0.093 & 0.016 & 38 & 5.79 & $0.0001 *$ & & & & & \\
\hline & & & NU vs. WC & 0.067 & 0.016 & 38 & 4.19 & $0.0002 *$ & & & & & \\
\hline & & & NP vs. WC & -0.026 & 0.016 & 38 & -1.60 & 0.1180 & -0.682 & 0.420 & 40 & -1.63 & 0.112 \\
\hline & \multirow[t]{6}{*}{$25^{\circ} \mathrm{C}$} & \multirow[t]{6}{*}{$0.0001 *$} & CA vs. NU & -0.128 & 0.013 & 50 & -9.67 & $0.0001 *$ & \multirow{6}{*}{$\begin{array}{r}0.528 \\
-0.163\end{array}$} & & & & \\
\hline & & & CA vs. NP & 0.022 & 0.013 & 50 & 1.67 & 0.1020 & & 0.347 & 52 & 1.52 & 0.134 \\
\hline & & & CA vs. WC & -0.010 & 0.013 & 50 & -0.83 & 0.4100 & & 0.347 & 52 & -0.47 & 0.640 \\
\hline & & & NU vs. NP & 0.150 & 0.013 & 50 & 11.30 & $0.0001 *$ & & & & & \\
\hline & & & NU vs. WC & 0.117 & 0.013 & 50 & 8.85 & $0.0001 *$ & & & & & \\
\hline & & & NP vs. WC & -0.033 & 0.013 & 50 & -2.49 & $0.0160 *$ & & & & & \\
\hline Blossoms & Fieldg & 0.223 & CA vs. NP & & & & & & 16.59 & 6.969 & 25 & 2.38 & $0.025 *$ \\
\hline & & & CA vs. WC & & mmon s & ope 1 & del follo & & -6.25 & 7.109 & 25 & -0.88 & 0.387 \\
\hline & & & NP vs. WC & & & & & & -22.84 & 8.095 & 25 & -2.82 & $0.009 *$ \\
\hline Fruit & Field & 0.116 & CA vs. NP & & & & & & 0.70 & 0.345 & 13 & 2.03 & 0.063 \\
\hline & & & CA vs. WC & & mmon s & ope 1 & del follo & & -0.15 & 0.345 & 13 & -0.43 & 0.671 \\
\hline & & & NP vs. WC & & & & & & -0.85 & 0.345 & 13 & -2.46 & $0.028 *$ \\
\hline
\end{tabular}

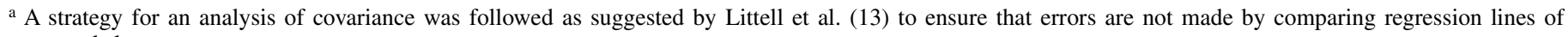
unequal slopes.

b Pair-wise comparisons between Carmel (CA), NePlus Ultra (NU), Nonpareil (NP), and Wood Colony (WC).

c An unequal slope model was used to compare cultivars when slopes of regression lines were unequal and slopes were tested for equality.

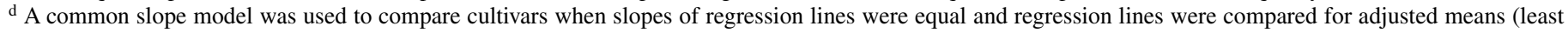
square means [LSMeans]) at the midpoint of the regression lines.

e Difference of LSMeans for a specific comparison.

f Value is significant at $P<0.05$.

$\mathrm{g}$ Variable temperatures under field conditions (text provides details).

Tissue alkalinization was not observed at all infection sites, indicating that the host sometimes may be successful to buffer the ammonia influx from the pathogen, and this likely prevents the establishment of an infection. Thus, a critical number of infections may be required to weaken the host and allow disease to develop, and this number may vary among host tissues and cultivars.

The wetness-temperature relationships for development of anthracnose on almond that we established in this study will allow us to design a forecast system that could determine timing of fungicide sprays and allow the implementation of more efficient management strategies for this important disease of almond in California. Moreover, exploitation of host resistance can be integrated as another strategy. The identification of different cultivar responses to anthracnose will help breeding programs in the selection of less susceptible genotypes and in choosing adequate cultivars in production areas with a high risk for the disease that ultimately will determine levels of disease control in disease management programs.

\section{LITERATURE CITED}

1. Adaskaveg, J. E., and Förster, H. 2000. Occurrence and management of anthracnose epidemics caused by Colletotrichum species on tree fruit crops in California. Pages 317-336 in: Colletotrichum: Host Specificity, Pathology, and Host-Pathogen Interactions. D. Prusky, S. Freeman, and M. B. Dickman, eds. The American Phytopathological Society, St. Paul, MN.

2. Adaskaveg, J. E., and Hartin, R. J. 1997. Characterization of Colletotrichum acutatum isolates causing anthracnose of almond and peach in California. Phytopathology 87:979-987. 
3. Bertetti, D., Gullino, M. L., and Garibaldi, A. 2009. Effect of leaf wetness duration, temperature and inoculum concentration on infection of evergreen azalea by Colletotrichum acutatum, the causal agent of anthracnose. J. Plant Pathol. 91:763-766.

4. Carisse, O., Bourgois, G., and Duthie, J. A. 2000. Influence of temperature and leaf wetness duration on infection of strawberry leaves by Mycosphaerella fragariae. Phytopathology 90:1120-1125.

5. Danneberger, T. K., Vargas, J. M., and Jones, A. L. 1984. A model for weather-based forecasting of anthracnose on annual bluegrass. Phytopathology 74:448-451.

6. Diéguez-Uribeondo, J., Förster, H., and Adaskaveg, J. E. 2003. Digital image analysis of internal light spots of appressoria of Colletotrichum acutatum. Phytopathology 93:923-930.

7. Dieguez-Uribeondo, J., Förster, H., and Adaskaveg, J. E. 2004. Temperature-wetness relationships for Colletotrichum acutatum infections on almond blossoms and leaves. (Abstr.) Phytopathology 94:S25.

8. Dieguez-Uribeondo, J., Förster, H., and Adaskaveg, J. E. 2008. Visualization of localized pathogen-induced $\mathrm{pH}$ modulation in almond tissues infected by Colletotrichum acutatum using confocal scanning laser microscopy. Phytopathology 98:1171-1178.

9. Diéguez-Uribeondo, J., Förster, H., Soto-Estrada A., and Adaskaveg, J. E. 2005. Subcuticular-intracellular hemibiotrophic and intercellular necrotrophic development of Colletotrichum acutatum on almond. Phytopathology 95:751-758.

10. Fitzell, R. D., and Peack, C. M. 1984.The epidemiology of anthracnose disease of mango: inoculum sources, spore production and dispersal. Ann. Appl. Biol. 104:53-59.

11. Fitzell, R. D., Peack, C. M, and Darnell, R. E. 1984. A model for estimating infection levels of anthracnose disease of mango. Ann. Appl. Biol. 104:451-458.

12. Förster H., and Adaskaveg, J. E. 1999. Identification of subpopulations of Colletotrichum acutatum and epidemiology of almond anthracnose in California. Phytopathology 89:1056-1065.

13. Littell, R. C., Milliken, G. A., Stroup, W. W., and Wolfinger, R. D. 1996. Analysis of covariance. Pages 171-200 in: SAS Systems for Mixed Models. SAS Institute, Inc., Cary, NC.

14. Madden, L. V. 1992. Rainfall and the dispersal of fungal spores. Pages 3979 in: Advances in Plant Pathology. J. H. Andrews, and I. Tommerup, eds. Academic Press, London.

15. Madden, L. V., Wilson, L. L., and Ellis, M. A. 1993. Field spread of anthracnose fruit rot of strawberry in relation to ground cover and ambient weather conditions. Plant Dis. 77:861-866.

16. Monroe, J. S., Santini, J. B, and Latin, R. 1997. A model defining the relationship between temperature and leaf wetness duration, and infection of watermelon by Colletotrichum orbiculare. Plant Dis. 81:739-742.

17. Montesinos, E., Moragrega, C., Llorente, I., Vilardell, P., Bonaterra, A., Ponti, I., Bugiani, R., Cavanni, P., and Brunelli, A. 1995. Development and evaluation of an infection model for Stemphylium vesicarium on pear based on temperature and wetness duration. Phytopathology 85:586-592.

18. Ogawa, J. M., and H. English. 1991. Anthracnose of almond. Pages 141142 in: Diseases of Temperate Zone Tree Fruit and Nut Crops. Publication 3345. University of California, Division of Agriculture and Natural Resources, Oakland.

19. Peres, N. A., Timmer, L. W., Adaskaveg, J. E., and Correll, J. C. 2005 Lifestyles of Colletotrichum acutatum. Plant Dis. 89:784-796.

20. Peres, N. A. R, Kim S., Beck, H. W., Souza, N. L., and Timmer, L. W. 2002. A fungicide application decision (FAD) support system for postbloom fruit drop of citrus (PFD). Online. Plant Health Progress doi:10.1094/PHP-2002-0731-01-RV.

21. Shaw, D. A., Adaskaveg J. E., and Ogawa, J. M. 1990. Influence of wetness period and temperature on infection and development of shot hole disease of almond caused by Wilsonomyces carpophilus. Phytopathology 80:749-756.

22. Timmer, L. W., and Brown, G. E. 2000. Biology and control of anthracnose diseases of citrus. Pages 300-316 in: Colletotrichum: Host Specificity, Pathology, and Host-Pathogen Interaction. D. Prusky, S. Freeman, and M. B. Dickman, eds. The American Phytopathological Society, St. Paul, MN.

23. Timmer, L. W., and Zitko, S. E. 1993. Relationships of environmental factors and inoculum levels to the incidence of postbloom fruit drop of citrus. Plant Dis. 77:501-503.

24. Timmer, L. W., and Zitko, S. E. 1996. Evaluation of a model for prediction of postbloom fruit drop of citrus. Plant Dis. 80:380-383.

25. Uddin, W., Serlemitsos, K., and Viji, G. 2002. A temperature and leaf wetness duration-based model for prediction of gray leaf spot of perennial ryegrass of turf. Phytopathology 93:336-343.

26. Wastie, R. L. 1972. Secondary leaf fall of Hevea brasiliensis: factors affecting the production, germination and viability of spores of Colletotrichum gloeosporioides. Ann. Appl. Biol. 72:273-282.

27. Wilson, L. L., Madden, L. V., and Ellis, M. A. 1990. Influence of temperature and wetness duration on infection of immature and mature strawberry fruit by Colletotrichum acutatum. Phytopathology 80:111-116. 